\title{
Thoughts on the Training Path of Fintech Talents Based on Project-Driven Teaching Method
}

\author{
Lili $\mathrm{Xu}^{*}$ \\ Shanghai Normal University Tianhua College \\ Shanghai 201815, China
}

\begin{abstract}
This paper discusses the cultivation of Fintech talents in universities under the industrial upgrading, and draws some conclusions: in the capacity building of students, the international communication ability is the most important, the coordination ability is second, and the communication, analysis and research ability are closely followed. From the perspective of social needs, we portray the job requirements and knowledge structure requirements. On this basis, the paper proposes that the project-driven teaching method can contribute to the path of talent training.
\end{abstract}

Keywords-Project-driven teaching; Talent development; Finance; Text mining

\section{INTRODUCTION}

The P2P industry has arisen in China since about 2012, and has rapidly developed from the initial dozens of online lending platforms to thousands ones. According to the original intention of the P2P industry, it is of positive significance to China's financial system. Small and micro enterprises in China have always had difficulty in financing, and a large number of small and micro enterprises have a strong financing demand. At the same time, under the pressure of inflation, a large number of ordinary people are facing the pressure of asset shrinkage, and it is impossible to outperform inflation just relying on bank deposits. In this context, P2P finance emerged out of nowhere and was widely accepted in the market.

However, according to the latest data released by the China Banking Regulatory Commission, the number of domestic online lending institutions has reduced by $57 \%$ compared with the beginning of last year. This is just the beginning. In July, Lufax, the head company of the P2P industry, also said that it would quit $\mathrm{P} 2 \mathrm{P}$ business. The sharp decline of $\mathrm{P} 2 \mathrm{P}$ industry is mainly due to regulatory pressure. In the past few years, P2P industry has situation occurred frequently, and even the founder of the platform ran away with money, which led to the extreme events that investors lost all the capitals at last. The reputation of the $\mathrm{P} 2 \mathrm{P}$ industry went worse, and almost became the synonym for financial fraud. In such situation, regulatory forces began to intervene in the P2P industry. And "three cuts" became the basic requirements of the management for the $\mathrm{P} 2 \mathrm{P}$ industry, that is, "the total number of platforms, the total scale of business, and the number of investors" should be significantly reduced. The contraction of P2P industry in the past few months is the true embodiment of "three cuts". In early July, the management made the last adjustments for the development of the P2P industry. "It clearly defined that in the next stage, we will steadily and orderly resolve the stock risks, take multiple measures to support and promote the benign withdrawal or smooth transformation of institutions, and maintain the stability of local economic and finance and social politics in all regions." $\mathrm{P} 2 \mathrm{P}$, once popular for a time, is gradually quitting the stage of history.

Fintech emphasizes the combination of finance and technology, with a focus on technology. Fintech technologies mainly include artificial intelligence technology, big data technology, Internet technology represented by mobile internet technology and Internet of Things technology, distributed technology represented by cloud computing and blockchain technology, and security technology represented by cryptography technology, quantum technology and biotechnology. The traditional financial industries such as banks and insurance achieved their own transformation and development relies on these technologies. Technological innovation has given birth to emerging fields such as intelligent investment consulting, supply chain finance, consumer finance, third-party payment, and regulatory technology. The promotion of science and technology to finance is no longer limited to the superficial aspects such as channels, but opens the deep integration of "finance + technology".( As shown in Fig. 1)

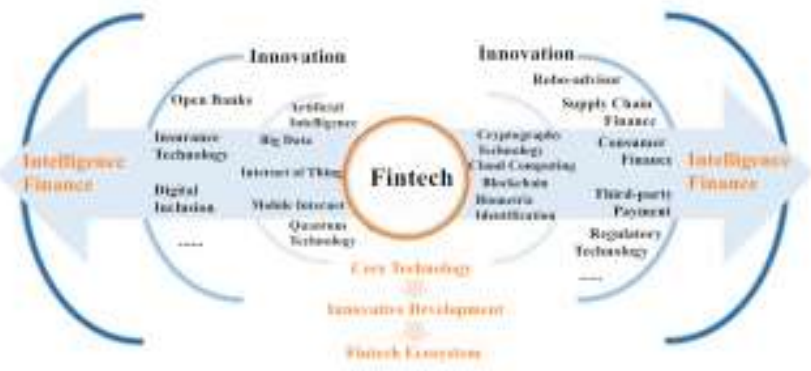

Fig. 1. Fintech ecosystem diagram

\section{ThOUGHTS ON THE CUltivation OF FinteCh TALENTS IN COLLEGES AND UNIVERSITIES UNDER THE INDUSTRIAL UPGRADING}

According to the "Report on the Fintech and Digital Financial Inclusion Development in China (2018)", China's Fintech industry is currently at the forefront of the world, and 
the Fintech talents are short-handed. The government has adopted various measures to promote the cultivation of Fintech talents. Based on the "13th Five-Year Plan for Talent Development in Shanghai's Financial Sector", "13th Five-Year Developing Catalogues for Urgently Needed Talents in Shanghai's Financial Sector" and "Report on the Development of Internet Financial Talents in Shanghai (2017)", the training orientation of Fintech talents in application-oriented undergraduate colleges should focus on training business financial talents, professional service financial talents and risk control and management financial talents for new Internet financial institutions and traditional financial institutions. They should have computer knowledge, financial knowledge, big data knowledge, marketing knowledge, business knowledge, professional practical ability and crossover learning and thinking ability.

\section{A. Construction of Talents Quality Training and Ability Map}

Based on the "13th Five-Year Developing Catalogues for Urgently Needed Talents in Shanghai's Financial Sector", we extract key words of the ability from the catalogues, as shown in Fig. 2.

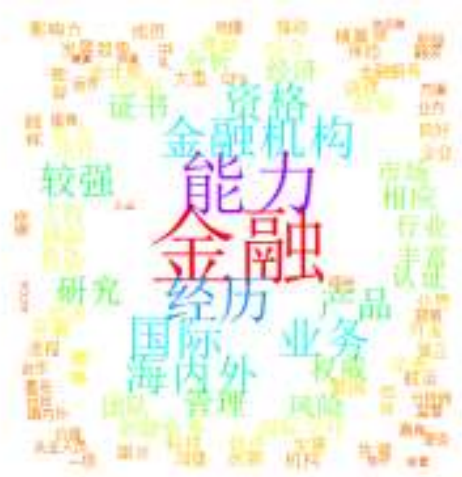

Fig. 2. Map of key words extraction

According to the keyword extraction, the "ability" has appeared 56 times in total. The semantic analysis of ability was further carried out, and the part of ability interception was customized, as shown in Table I.

TABLE I. CATAloguES OF ABILITY IN CUSTOM Dictionary

\begin{tabular}{|c|c|c|c|c|c|}
\hline Number & Terms & Custom Dictionary & Number & Terms & $\begin{array}{c}\text { Custom } \\
\text { Dictionary }\end{array}$ \\
\hline 1 & Ability of strategic planning & Strategic planning & 17 & Ability of study and anticipation & $\begin{array}{c}\text { Study, } \\
\text { anticipate }\end{array}$ \\
\hline 2 & Ability of leadership and decision-making & Decision-making & 18 & $\begin{array}{l}\text { Ability of communication and } \\
\text { coordination }\end{array}$ & $\begin{array}{c}\text { Communicate, } \\
\text { coordinate }\end{array}$ \\
\hline 3 & Ability of team construction & Team construction & 19 & Ability of judgment and analysis & $\begin{array}{c}\text { Judgment, } \\
\text { analysis }\end{array}$ \\
\hline 4 & Ability of organization and coordination & $\begin{array}{l}\text { Organize and } \\
\text { coordinate }\end{array}$ & 20 & Ability of study and anticipation & $\begin{array}{c}\text { Study, } \\
\text { anticipation }\end{array}$ \\
\hline 5 & Ability of international communication & $\begin{array}{c}\text { International } \\
\text { communication }\end{array}$ & 21 & Ability of study and analysis & $\begin{array}{c}\text { Study, } \\
\text { analysis }\end{array}$ \\
\hline 6 & Ability of innovation ability & innovate & 22 & Ability of crossover learning & $\begin{array}{l}\text { Crossover } \\
\text { learning }\end{array}$ \\
\hline 7 & Ability of comprehensive management & management & 23 & Ability of adaption & adaption \\
\hline 8 & Ability of team-work & Team work & 24 & Ability of marketing public relation & $\begin{array}{c}\text { Marketing } \\
\text { public relation }\end{array}$ \\
\hline
\end{tabular}

In the custom dictionary, the ability requirements are segmented, sorted and the word cloud was drawn, whose results are shown in Fig. 3. It can be seen that "international communication" appears 14 times, "coordination" 13 times, followed by communication, analysis, research, and the ability requirements for crossover learning occurred as well.

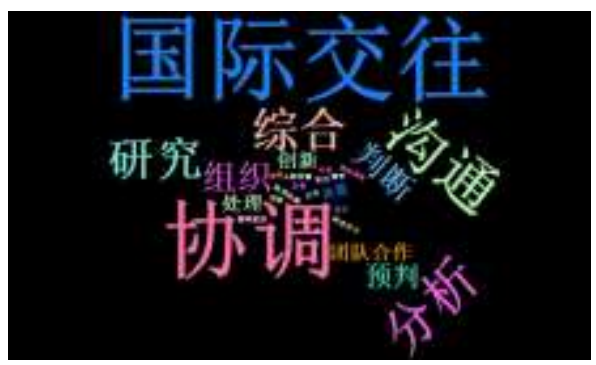

Fig. 3. Statistical map of word frequency of ability requirement
B. Analysis of Talent Cultivation from the Perspective of Social Needs

Based on the "13th Five-Year Developing Catalogues for Urgently Needed Talents in Shanghai's Financial Sector", we made word segmentation of experiences and position, marked the part of speech for word segmentation, then screened out the words of part of speech of nouns and made word frequency statistics. Some selected results are shown in Table II. 
TABLE II. Statistical Results OF SOME ENTRIES OF SELECTED NOUNS AFTER WORD SEGMENTATION

\begin{tabular}{|c|c|c|c|}
\hline terms(nouns) & $\begin{array}{c}\text { Word } \\
\text { frequency }\end{array}$ & terms(nouns) & $\begin{array}{c}\text { Word } \\
\text { frequency }\end{array}$ \\
\hline Finance & 74 & Rules & 4 \\
\hline Ability & 57 & Internet & 4 \\
\hline Experience & 43 & Structure & 4 \\
\hline International & 38 & Financial risk & 4 \\
\hline $\begin{array}{l}\text { Financial } \\
\text { institution }\end{array}$ & 38 & Economic benefit & 4 \\
\hline Business & 36 & Commodity & 4 \\
\hline Qualification & 34 & Literacy & 4 \\
\hline Product & 29 & Culture & 4 \\
\hline Certificate & 22 & Cultural industry & 4 \\
\hline Risk & 20 & Consciousness & 4 \\
\hline Industry & 19 & Professional knowledge & 4 \\
\hline Economy & 18 & Capital & 4 \\
\hline Market & 18 & Asset & 4 \\
\hline Technology & 11 & Decision & 3 \\
\hline $\begin{array}{c}\text { Financial } \\
\text { service }\end{array}$ & 9 & Data mining & 3 \\
\hline Actuary & 8 & Credit & 3 \\
\hline List price & 5 & Innovation ability & 2 \\
\hline Supply chain & 5 & entrepreneurship & 2 \\
\hline
\end{tabular}

According to the statistical results in Table II, the word "finance" appeared 74 times, and the word "technology" appeared 11 times.

Furthermore, we summarize the language descriptions of knowledge requirements, and the results are shown in Table III.
TABLE III. Statistical TABle OF KNOWLEDGE StRUCTURE REQUIREMENTS

\begin{tabular}{|c|l|}
\hline & Actuarial Science \\
& Supply Chain Finance(Inancial Technology) \\
Shipping Finance(Financial Technology) \\
Offshore Finance(Financial Technology) \\
Reinsurance(Financial Technology) \\
Leasing Business \\
Requirements of Knowledge & Factoring Business \\
Structure & Financial Risk Control \\
& Law/Legislation \\
& Marketing Management \\
& Financial Products \\
& Finance and Tax \\
& Financial Accounting \\
& Auditing \\
& Economics \\
\hline
\end{tabular}

\section{Summary}

Through the exploration of the text, Chinese word segmentation and word frequency statistics, we got the focus of the quality and ability in talent training, including 26 ability descriptions, 14 times of "international communication", 13 times of "coordination", followed by communication, analysis, research, and the ability requirements for crossover learning occurred as well. In addition, in the analysis of talent cultivation from the perspective of social demand, the positions and knowledge requirements of chartered financial analyst, supply chain finance, shipping finance, offshore finance, financial risk manager, etc. mentioned in the position demand and knowledge structure demand belong to the category of Fintech, which provide data and demand support for the path design of the following talent training.

Back to the training objectives of Fintech talents, how can our training program and curriculum system meet the needs of ability, position and knowledge structure? How to comprehensively analyze the focus of quality and ability in the training of Fintech talents? Computers, mathematics, economics and finance are the troika, and programming ability is the basic foundation. We put forward a preliminary idea of how to achieve the goal of talent training in the project-based teaching, as shown in Fig. 4. 


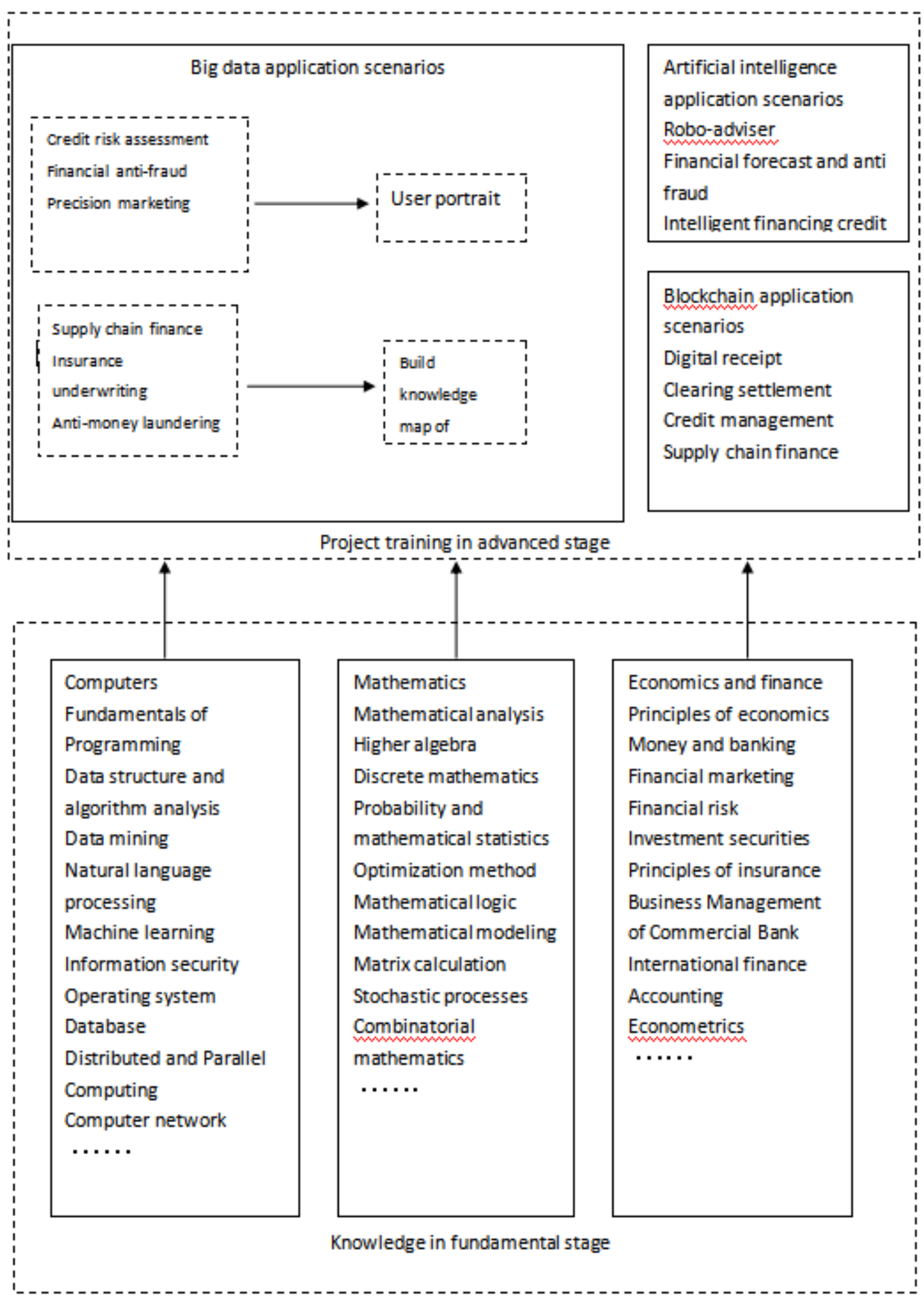

Fig. 4. Project-based training map of Fintech talents

\section{THE IMPLEMENTATION OF THE TALENTS TRAINING IN "PROJECT-DRIVEN" TEACHING}

Project-driven teaching method means that in the teaching process, complete a specific project as a clue, cleverly embed the teaching content in each project, so that students can pose their own questions, and solve problems by themselves after thinking and their teacher's instructions. Meanwhile, students have cultivated the consciousness of innovation, the ability of innovation and the habit of independent learning, and have learned how to find problems, think about them and find solutions.

But where does the project come from? How to motivate students to finish projects efficiently and excellently? How will 
the final results of the project be implemented? How to evaluate students' project completion? We have some discussions on these questions.

\section{A. Teachers' Cases and Experiment Contents}

The teaching content should not be isolated knowledge points, or separated from the practice and industry frontier cases and experimental design, but should integrate the teachers' scientific research topics and even immature ideas, industry frontier technology into the teaching content, so that the content is rich, vivid and real-time update. In this way, like snowball, students learn by doing and teachers research by teaching, forming a network map of teaching objectives based on curriculum nodes, and finally achieving the goal of talent training.

\section{B. The Horizontal Topic of Industry-education Integration}

If teachers and students make some progress in the cases and experiment projects, and make some achievements, the development of the horizontal topic of the integration of industry and education will make sense. In other words, the previous curriculum cases and experimental projects are actually incubation projects, which lay the foundation for the integration of industry and education. With the help of the horizontal topic of integration of industry and education, many excellent universities have made a group of students participate in and stand out, not only graduate students, doctoral students, but also undergraduate students are full of enthusiasm.

In the teaching process, each chapter or specific experiment in the textbook is designed as a project, or some courses can be designed as a large project, and then the large project is divided into several small projects, and each section is composed of one or several small projects. The establishment of experimental projects in each stage is determined by the overall arrangement of students' current knowledge and teaching content.

\section{CONCLUSION AND EXPECTATION}

This paper discusses the cultivation of Fintech talents in universities under the industrial upgrading, and draws some conclusions: in the capacity building of students, the international communication ability is the most important, the coordination ability is second, and the communication, analysis and research ability are closely followed. From the perspective of social needs, we portray the job requirements and knowledge structure requirements and get some interesting conclusion.

This paper is based on the "13th Five-Year Developing Catalogues for Urgently Needed Talents in Shanghai's Financial Sector". It conducts text mining and keyword extraction on the ability requirements and position demand mentioned in the catalogue. The source of the material is single, and we can further optimized the ability map and position map with the help of big data on the Internet. The incentive method mentioned in the project-driven teaching method is based on Maslow's hierarchy of needs theory. The theory is single, and the subsequent design can be further combined with the students' performance in project practice or in the form of questionnaire.

\section{REFERENCES}

[1] Zhao Gaomin, et al. Analysis of Visualization on the Study of Internet Finance in China Based on Knowledge Domains Map [J]. Journal of Commercial Economics, 2019 (2). (In Chinese).

[2] 13th Five-Year Developing Catalogues for Urgently Needed Talents in Shanghai's Financial Sector,2017. (In Chinese). http://www.ljzfin.com/news/info/36447.html.

[3] Zhang Yun, et al. Reconstruction of the Experimental Training System for the Training of Financial Talents in Fintech Era, China University Teaching, 2020 (1). (In Chinese).

[4] Xu Dexiang. Research on Cross-strait Innovative Talents Cultivation in Fintech Era, Straits Science, 2019.9. (In Chinese).

[5] Xu Zhenguo. Reflection and Reform on the Training Mode of Financial Talents in the Fintech Era, Subject Exploration, 2019. (In Chinese).

[6] Hu Ping. What Kind of Fintech Talents We Need, Financial Times, 2020 4. (In Chinese). 